\title{
The Midwest Stream Quality Assessment_-Influences of Human Activities on Streams
}

Healthy streams and the fish and other organisms that live in them contribute to our quality of life. Extensive modification of the landscape in the Midwestern United States, however, has profoundly affected the condition of streams. Row crops and pavement have replaced grasslands and woodlands, streams have been straightened, and wetlands and fields have been drained. Runoff from agricultural and urban land brings sediment and chemicals to streams. What is the chemical, physical, and biological condition of Midwestern streams? Which physical and chemical stressors are adversely affecting biological communities, what are their origins, and how might we lessen or avoid their adverse effects?

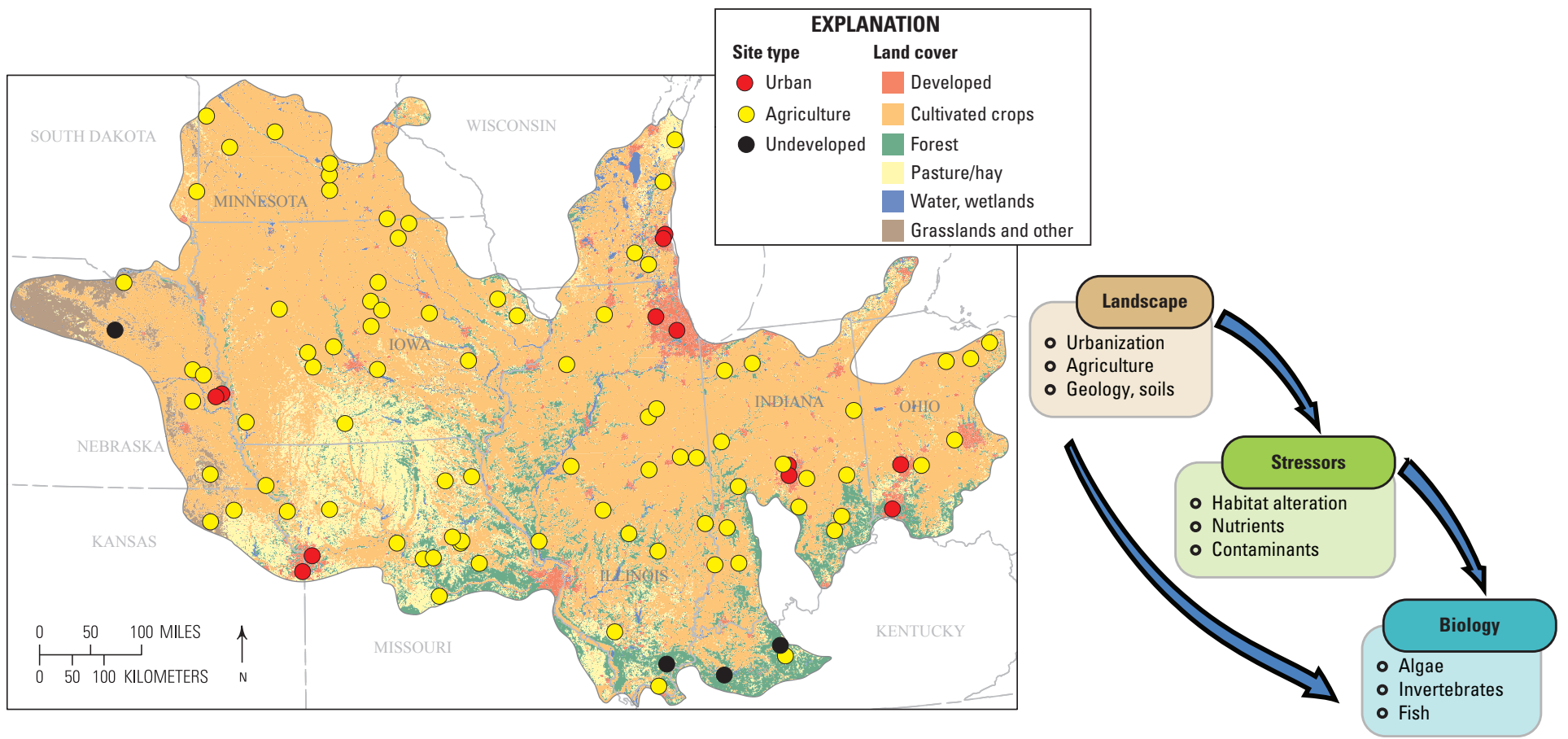

Sites sampled during the Midwest Stream Quality Assessment, May-August 2013.

In 2013, the U.S. Geological Survey (USGS) conducted the Midwest Stream Quality Assessment (MSQA) to evaluate how human activities affect the biological condition of Midwestern streams. In collaboration with the U.S. Environmental Protection Agency (EPA) National Rivers and Streams Assessment, the USGS sampled 100 streams, chosen to be representative of the different types of watersheds in the region (Garrett and others, 2017). Biological condition was evaluated based on the number and diversity of fish, algae, and invertebrates in the streams. Changes to the physical habitat and chemical characteristics of the streams - "stressors" in the diagram above - were assessed, and their relation to landscape factors and biological condition was explored by using mathematical models. The data and models help us to better understand how the human activities on the landscape are affecting streams in the region. 


\section{Biological Conditions}

\section{Algae}

Algae are plant-like organisms at the base of the aquatic food chain. They tend to respond rapidly to changes in their environment, which makes them especially sensitive indicators of effects of human activities on aquatic life in streams. Algal sampling by MSQA focused on diatoms, a common type of algae that generally are attached to hard surfaces such as rocks and wood.

The healthiest algal communities were in MSQA streams with rock and gravel substrate, cool water, and low levels of herbicides (Munn and others, 2018). The MSQA streams with more finegrained sediment - silt and sand rather than gravel — had fewer "sensitive" diatoms, those most commonly lost as a stream is degraded. Sensitive diatom abundance also was lower in streams with warmer water temperature and higher levels of triazine herbicides, such as atrazine.

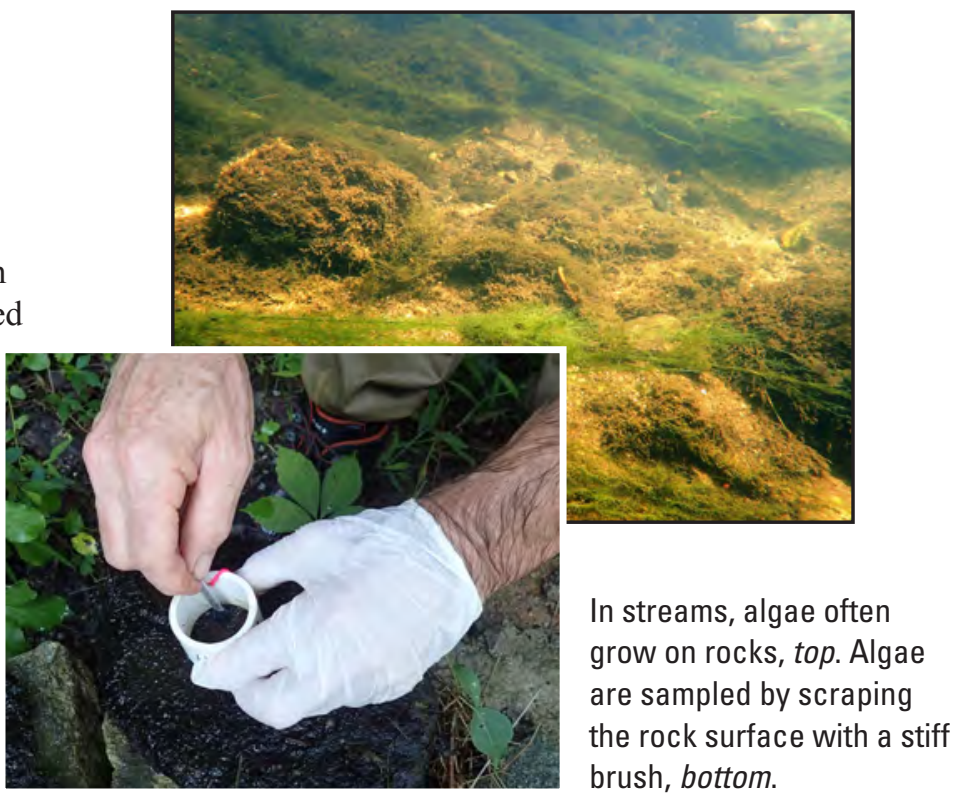

\section{Invertebrates}

Invertebrates - animals without backbones - include insects (such as mayflies and caddisflies), mollusks (such as snails and clams), worms, and crustaceans (such as amphipods and crayfish). Invertebrates are a critical part of the aquatic food web, both as predators and as food for fish and birds.

As with algae, physical and chemical alterations to MSQA streams adversely affected invertebrate communities (Waite and Van Metre, 2017). Habitat variables - excessive finegrained sediment, riparian condition, stream velocity, and channel shape-were associated with degradation of the invertebrate community, such as loss of sensitive insect species. These variables are affected by stream straightening and human development near streams. Ammonia (a form of nitrogen) and pesticides in streams, in particular the pyrethroid insecticide bifenthrin, also were associated with degradation of invertebrate communities (Rogers and others, 2016; Moran and others, 2017; Waite and Van Metre, 2017).
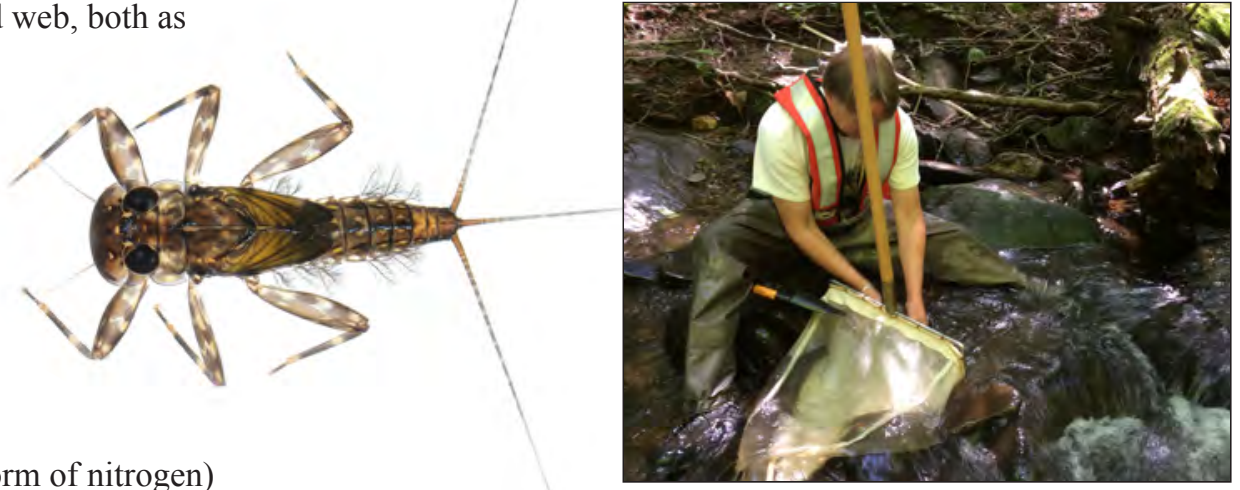

Mayfly larvae are among the invertebrates sampled in streams, left (Alan Cressler, USGS). A biologist uses a fine-mesh net to collect invertebrates from a stream riffle, right.

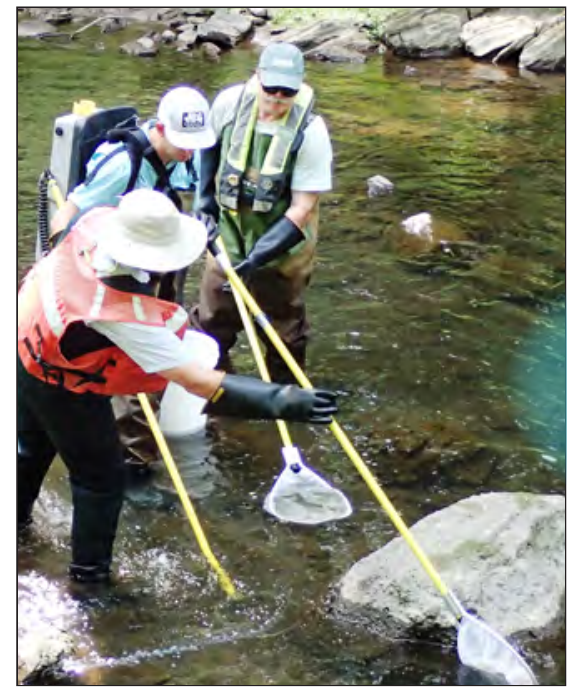

Fish are electroshocked and netted for field identification, then released, left. Green Sunfish was the most common species in MSOA streams, right.

\section{Fish}

Fish occupy many roles in stream ecosystems. Some species are predators, consuming invertebrates and other fish; other species consume algae and plants. Fish are an important food source for wildlife and support substantial economic activity related to sport fishing - the American Sportfishing Association estimates over $\$ 15$ billion in annual economic activity for the Midwestern States included in the MSQA (American Sportfishing Association, 2013).

Fish species diversity is relatively high in Midwestern streams and rivers-135 fish species were identified in MSQA sampling, with the Green Sunfish being the most common

(Meador and Frey, 2018). Total nitrogen was the most important stressor affecting fish communities, and fish species abundance decreased as nitrogen concentrations increased. Excessive fine sediment covering the streambeds also was related to the loss of fish species, particularly those species that require gravel or cobble streambeds to reproduce. Pesticides and other contaminants do not appear to be affecting fish communities in most of the streams studied (Nowell and others, 2018). 


\section{Habitat Alteration}

\section{Loss of Riparian Zone}

The land adjacent to a stream is called the riparian zone. Undisturbed riparian zones provide shelter and food for aquatic and terrestrial organisms, shade the stream with trees, and inhibit runoff from agricultural and urban land from entering the stream. Stream straightening and encroachment of croplands and urban areas has led to widespread disturbance of riparian zones along Midwestern streams.

Riparian zone disturbance was associated with adverse effects on invertebrate (Waite and Van Metre, 2017) and algal (Munn and others, 2018) communities in MSQA streams. Conversely, some MSQA streams with undisturbed forested riparian zones had healthy invertebrate communities even though the watershed was heavily developed. Massies Creek near Wilberforce, Ohio, for example, has a watershed that is 83 percent row crop, but its riparian zone is forested and only 7 percent developed. Massies Creek has a healthy invertebrate community, as reflected by an invertebrate multimetric index (MMI) of 79 (scale 0-100). Three Mile Creek near Ghent, Minn., has a watershed with less row crop (76 percent) but a more disturbed riparian zone ( 60 percent developed), and its invertebrate community is less robust (MMI of 49).

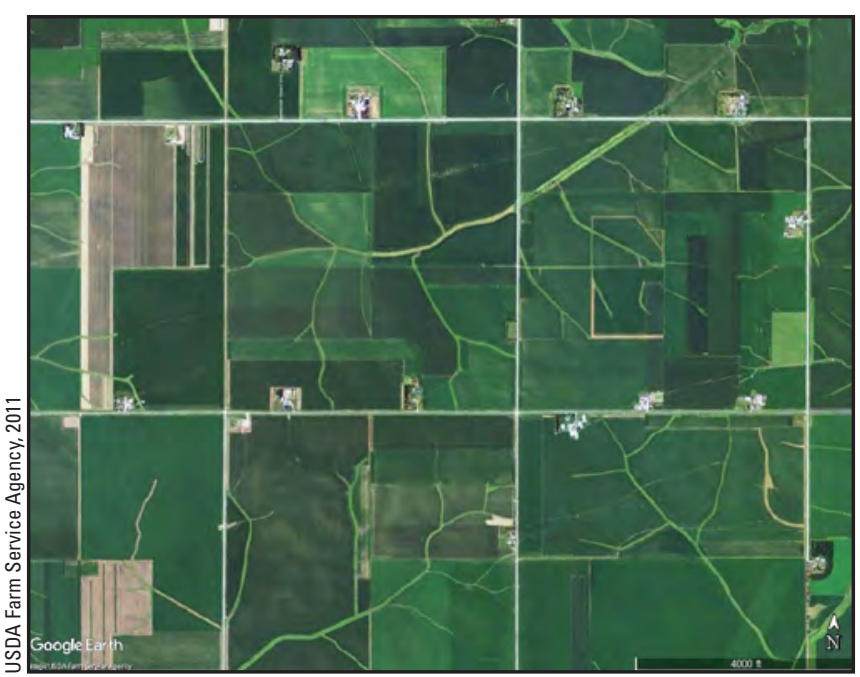

This satellite image from northeast lowa illustrates the extensive modification of the Midwestern landscape by agriculture. The streams are visible as light green lines over which a grid of rural roads has been superimposed. The streams are devoid of riparian woodlands and, in many cases, straightened, which can cause severe erosion of the stream channel.

\section{Sediment}

Excessive amounts of fine sediment bury gravel and cobble that are critical habitat for many algae, invertebrates, and fish, and fine sediment in the water column restricts penetration of light needed for plant growth.

Excessive amounts of fine sediment in the streambed or water column in MSQA streams were related to degraded algal, invertebrate, and fish communities (Waite and Van Metre, 2017; Meador and Frey, 2018; Munn and others, 2018). Streambank and channel erosion contributed almost two-thirds of the fine sediment in streams, on average, whereas soil erosion accounted for just one-third (Gellis and others, 2017). Knowing the dominant sources of fine sediment may help guide management efforts to protect and restore streams.

\section{Nutrient Enrichment}

MSQA streams with higher levels of nutrients were more likely to have degraded algal, invertebrate, and fish communities (Waite and Van Metre, 2017; Meador and Frey, 2018; Munn and others, 2018). The principal nutrients are nitrogen and phosphorus, which are contained in fertilizer and animal wastes. Large amounts of nutrients in streams promote excessive growth of algae, which can lead to oxygen depletion, fish kills, and toxic algal blooms.

Agricultural fertilizer is a major source of nutrients to Midwestern streams, as evidenced by the link between watershed corn production and nitrate concentrations (graph at right). Nitrate accounts for most of the total nitrogen in MSQA streams, which was the most important stressor identified for fish (Meador and Frey, 2018). The MSQA also demonstrated how annual rainfall patterns affect nitrate concentrations in streams. During the 2012 drought, nitrogen built up in the soils because agricultural crops grew poorly and did not use much nitrogen, and because there was little rainfall to cause nitrogen runoff. The 2012 drought was followed by heavy rains in 2013, and rainfall runoff in 2013 caused nitrate concentrations in many Midwestern streams to be higher than normal during the MSQA sampling (Van Metre and others, 2016).

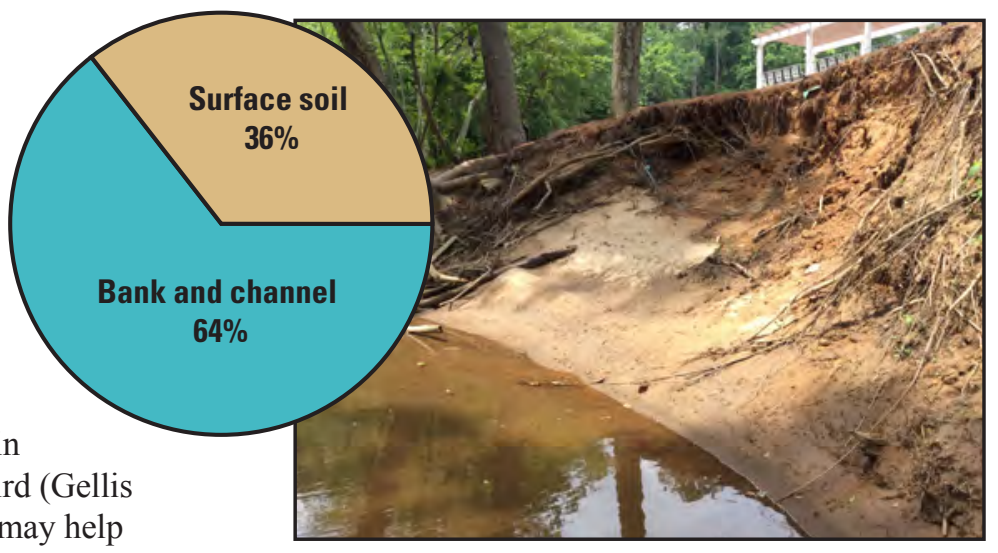

Erosion of streambanks contributes about twice as much sediment to MSQA streams, on average, than does erosion of soils (Gellis and others, 2017).

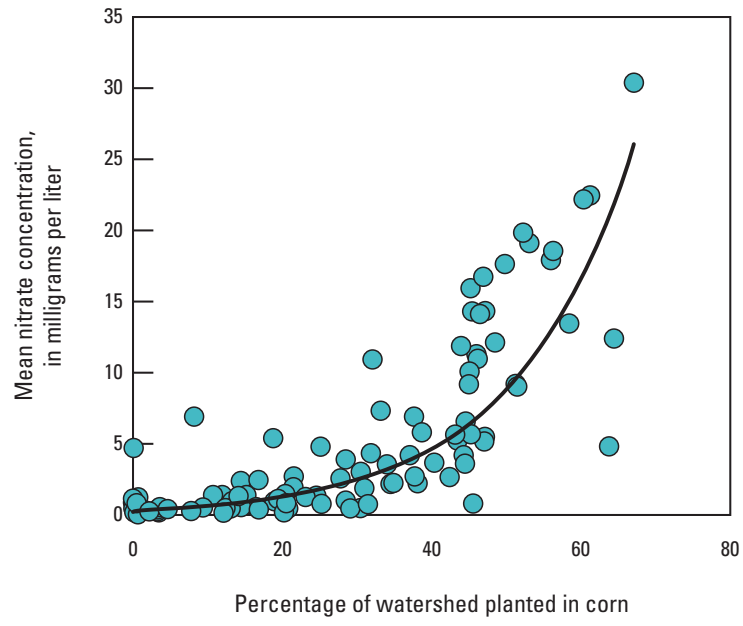

Corn production in watersheds is strongly associated with concentrations of nitrate in MSOA streams. For the $36 \mathrm{MSQA}$ streams with less than 20 percent of the watershed planted in corn, the mean nitrate concentration was only 1.2 milligrams per liter. 


\section{Contaminants}

\section{Pesticides in Water}

Of the 228 pesticides analyzed, 184 were detected at least once in MSQA stream samples (Mahler and others, 2017; Nowell and others, 2018). During the 3-month sampling period, an average of 54 pesticides were detected at each site and an average of 25 pesticides were detected in each water sample. Pesticide concentrations more frequently exceeded aquatic life benchmarks (levels expected to be harmful) for invertebrates and algae than for fish (Nowell and others, 2018). Chronic (sublethal) or acute (potentially lethal) toxic effects to invertebrates were indicated in 55 percent of streams, and 12 percent of those streams had at least one potentially lethal short-term spike in insecticide concentration during the study. Water in agricultural streams, which had higher concentrations of herbicides than urban streams, was predicted to be most toxic to algae, whereas water in urban streams, which had higher concentrations of insecticides than agricultural streams, was predicted to be most toxic to invertebrates (right).

The neonicotinoid insecticide imidacloprid, pyrethroid insecticides, triazine herbicides, and the pesticide toxicity index (PTI) - a measure of estimated toxicity of pesticide mixtures (Shoda and others, 2016) — were significantly related to adverse effects on algal and invertebrate communities in MSQA streams (Waite and Van Metre, 2017; Munn and others, 2018). Bifenthrin, a pyrethroid insecticide that accumulates in sediment, also was associated with degraded invertebrate communities (Rogers and others, 2016; Moran and others, 2017; Van Metre and others, 2017; Waite and Van Metre, 2017).

\section{Contaminants in Sediment}

Sediment from the MSQA streams was analyzed for pesticides, polychlorinated biphenyls (PCBs), polycyclic aromatic hydrocarbons (PAHs), and metals (not all compounds were analyzed at all sites). Many of these chemicals accumulate in sediment and can harm biota. Sediment from 99 of the 100 streams also was tested for toxicity to 2 invertebrate species in the laboratory.

MSQA streams have relatively uncontaminated sediment. Concentrations of sediment-bound contaminants were below sediment-quality benchmarks for the protection of aquatic life, and the incidence of toxicity in laboratory tests was low (Moran and others, 2017), in part because bed sediments were diluted by eroded streambank sediment in many streams (Gellis and others, 2017). Sediment toxicity found in laboratory tests was associated with the insecticide bifenthrin (see below). Sediment from urban streams had significantly higher concentrations of metals, PCBs, PAHs, and several pesticides (including chlordane and DDE) than sediment from agricultural streams (Moran and others, 2017).
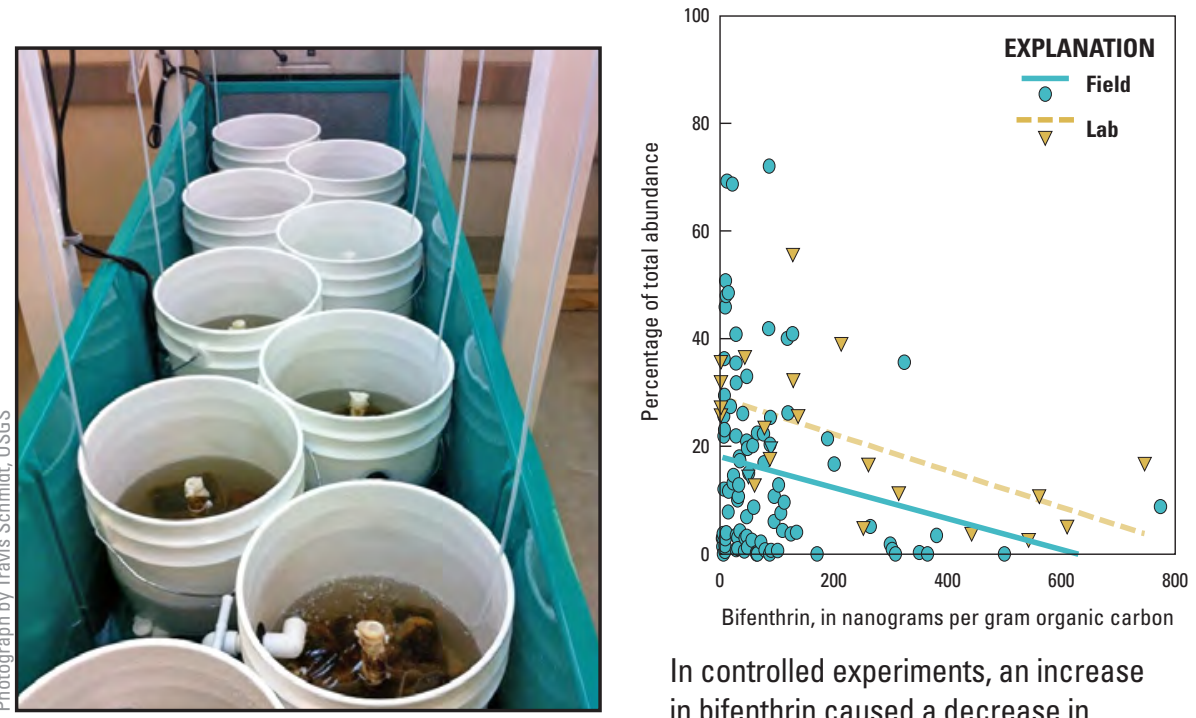

Artificial "streams" (mesocosms) were used to test the effects of bifenthrin on natural invertebrate communities.

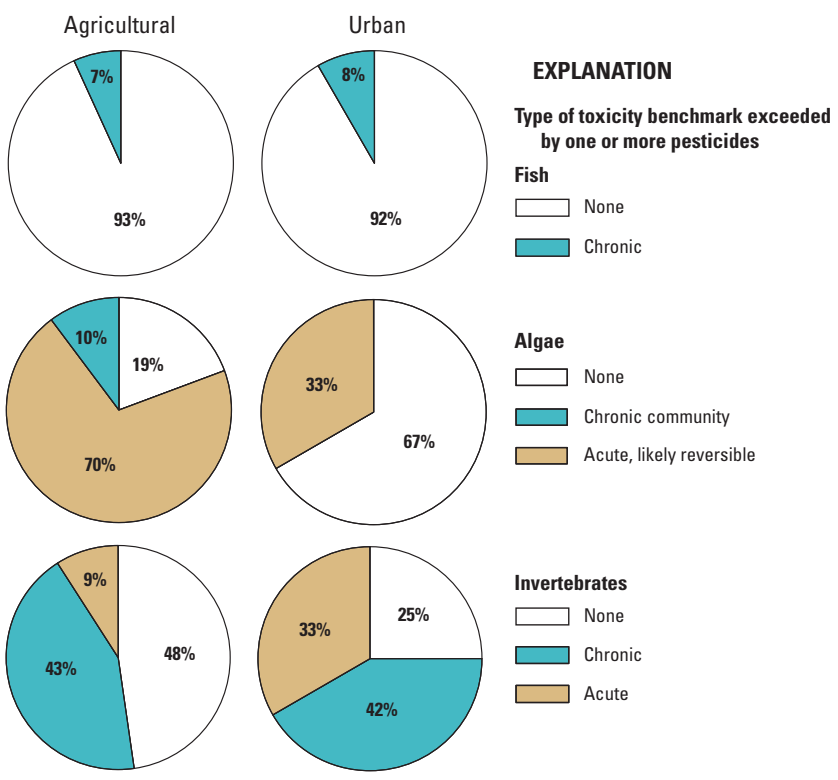

Water in the majority of the $100 \mathrm{MSQA}$ streams is likely to be toxic to aquatic organisms.

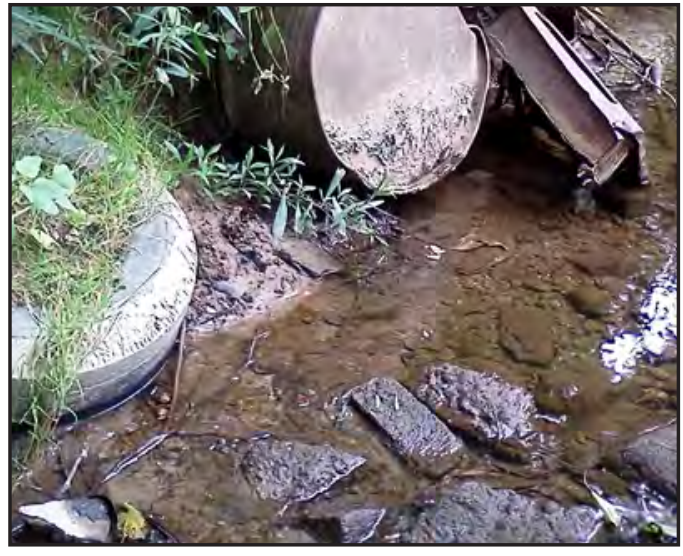

Sediment in urban streams, such as Wolf Creek in Cincinnati, Ohio, is frequently contaminated.

\section{Bifenthrin Effects}

Bifenthrin, a widely used pyrethroid insecticide that collects in sediment, is highly toxic to aquatic invertebrates. Mesocosm experiments demonstrated that multiple ecological responses to bifenthrin occur at concentrations similar to those measured in MSQA stream sediment (Rogers and others, 2016). Low levels of bifenthrin altered the timing of adult insect emergence, which could disrupt reproduction and affect the terrestrial food web. Moderate and high levels of bifenthrin were lethal to some sensitive species, such as scrapers (invertebrates that consume algae they scrape from rocks). The disappearance of scrapers accelerated algal growth. The results of the mesocosm experiments were consistent with MSQA results, which reported a decrease in herbivorous mayflies with higher bifenthrin concentrations in streams. 


\section{Ecological Models Connect the Landscape and Instream Stressors to Measures of Biological Condition in the MSOA Streams}

Landscape: Human development causes chemical and physical changes to the natural landscape, leading to instream stressors.
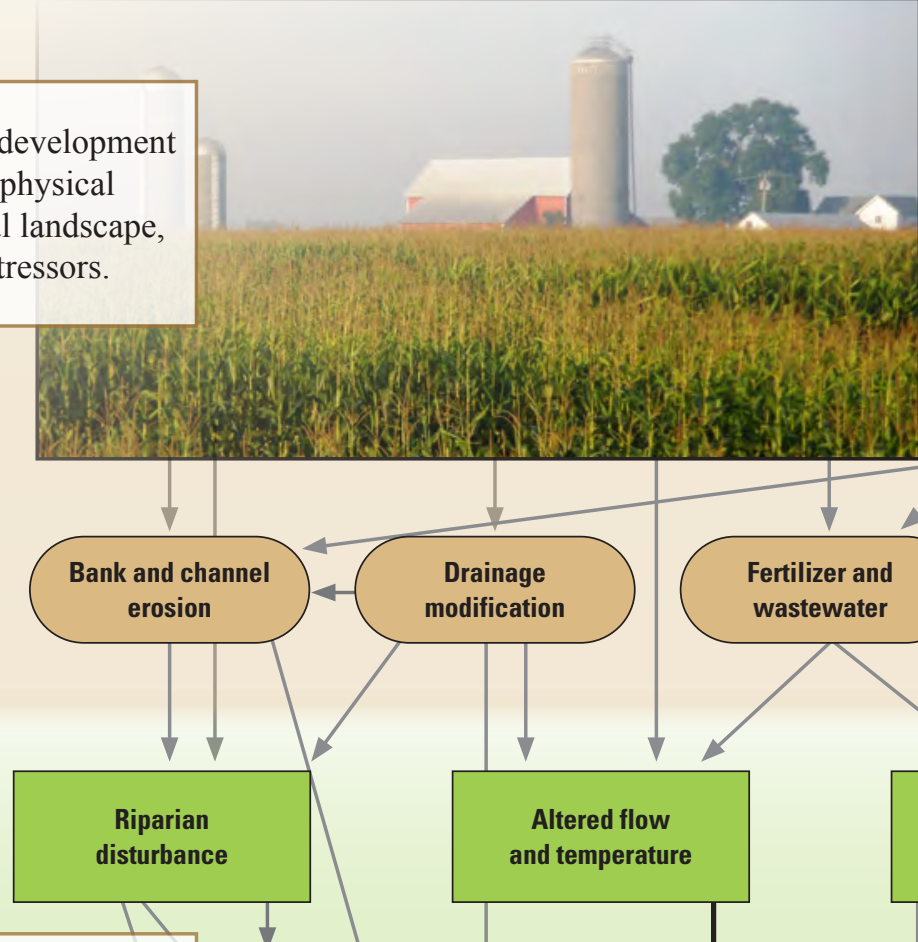

Stressors: The specific factors that degrade biological conditions in the streams, as indicated by ecological modeling results, are linked to agricultural and urban land use.

Biological condition: Biota living in the streams respond to different combinations of stressors, depending on the species and the conditions in each stream.

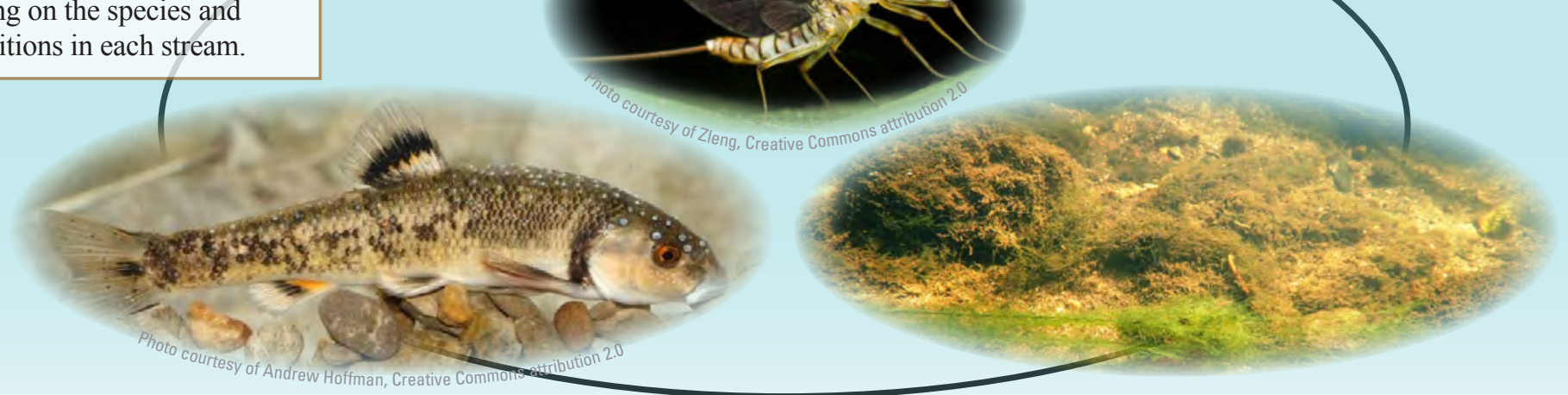

Ecological models have associated instream stressor variables (green boxes) with measures of the condition of biological communities in MSQA streams, as represented by arrows. For example, one model identified five stressors associated with the invertebrate multimetric index (MMI), an overall measure of the health of the invertebrate community (black arrows) (Waite and Van Metre, 2017). Other models demonstrate how consequences of agricultural and urban land use (tan ovals) are related to instream stressors (green boxes). 


\section{Conclusions}

What have the results of the MSQA told us about stream quality in the Midwest and about which stressors are most important?

First, there are no pristine streams in the region, as indicated, for example, by a minimum of 28 pesticides detected in water at any site (Van Metre and others, 2017).

Second, no single stressor or stressor type is responsible for all of the changes to the biological communities - for almost every stream and every measure of biological condition, many stressors, both physical and chemical, are implicated. Further, each site has a unique mix of stressors, as illustrated by the site scorecards on the Regional Stream Quality Assessments (RSQA) website. These findings suggest that improving stream conditions across the region will require multiple approaches. In spite of this complexity, there are some consistent findings across sites and biological communities. Habitat, in particular excess fine sediment and the condition of the channel and riparian zone, are important to all biological communities. Pesticides, specifically the triazine herbicides and the pyrethroid insecticides, are affecting algae and invertebrates. Lastly, managing for one group of stressors by, for example, preserving or restoring riparian-zone buffers along streams might reduce other stressors as well.

\section{Find Out More About Midwestern Streams}

Data, publications, and results, including a scorecard of the condition of each MSQA stream, can be found on the RSQA website at http://webapps. usgs.gov/RSQA/.

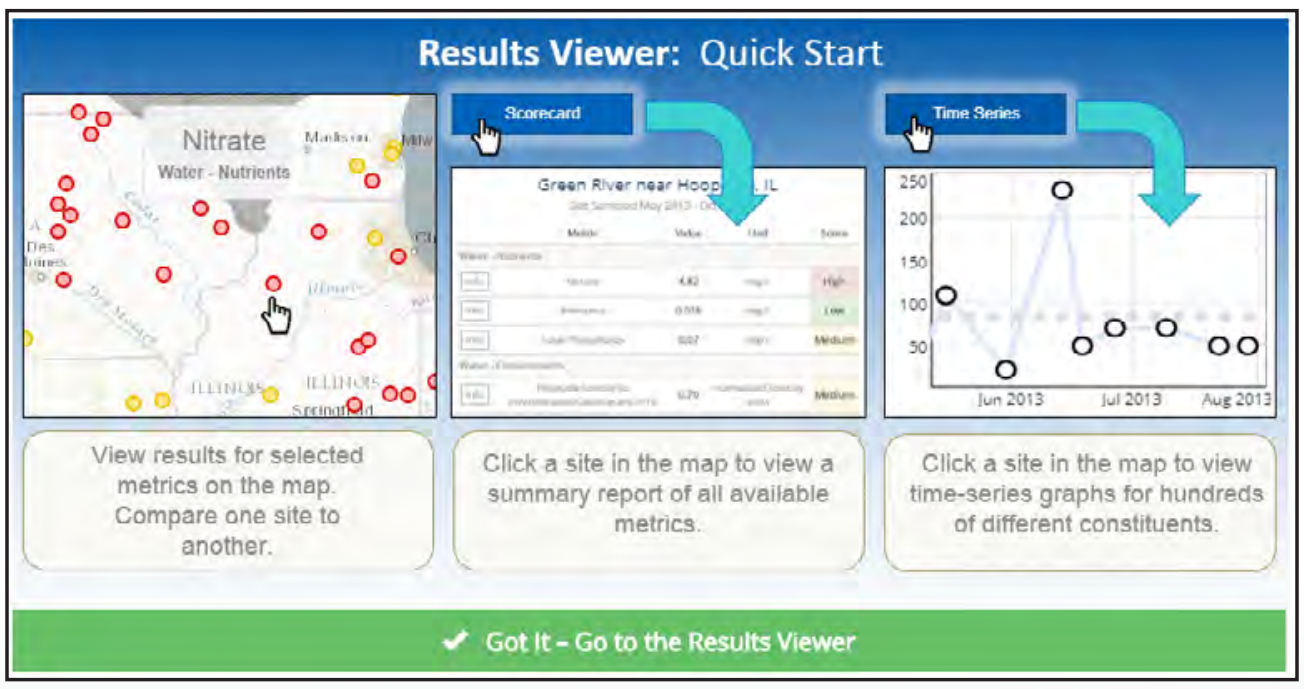

\section{References}

American Sportfishing Association, 2013, Sportfishing in America, an economic force for conservation, accessed September 25, 2017, at http://www. southwickassociates.com/wp-content/uploads/downloads/2013/01/SWA-001Sportfishing-in-America-Report-FINAL.pdf.

Garrett, J.D., Frey, J.W., Van Metre, P.C., Journey, C.A., Nakagaki, N., Button, D.T., and Nowell, L.H., 2017, Design and methods of the Midwest Stream Quality Assessment (MSQA), 2013: U.S. Geological Survey Open-File Report $2017-$ 1073, 59 p., accessed February 2018 at http://dx.doi.org/10.3133/ofr20171073.

Gellis, A.C., Fuller, C.C., and Van Metre, P.C., 2017, Sources and ages of finegrained sediment to streams using fallout radionuclides in the Midwestern United States: Journal of Environmental Management, v. 194, p. 73-85, accessed February 2018 at http://dx.doi.org/10.1016/j.jenvman.2016.06.018.

Mahler, B.J., Van Metre, P.C., Burley, T.E., Loftin, K.A., Meyer, M.T., and Nowell, L.H., 2017, Similarities and differences in occurrence and temporal fluctuations in glyphosate and atrazine in small Midwestern streams (USA) during the 2013 growing season: Science of the Total Environment, v. 579, p. 149-158, accessed February 2018 at http://dx.doi.org/10.1016/j.scitotenv.2016.10.236.

Meador, M., and Frey, J., 2018, Relative importance of water-quality stressors in predicting fish community responses in Midwestern streams: Journal of the American Water Resources Association, accessed March 2018 at http://dx.doi. org/10.1111/1752-1688.12646.

Moran, P.W., Nowell, L.H., Kemble, N.E., Mahler, B.J., Waite, I.R., and Van Metre, P.C., 2017, Influence of sediment chemistry and sediment toxicity on macroinvertebrate communities across 99 wadable streams of the Midwestern USA: Science of the Total Environment, v. 599-600, p. 1469-1478, accessed February 2018 at http://dx.doi.org/10.1016/j.scitotenv.2017.05.035.

Munn, M.D., Waite, I., and Konrad, C.P., 2018, Assessing the influence of multiple stressors on stream diatom metrics in the upper Midwest, USA: Ecological Indicators, v. 85, p. 1239-1248, accessed February 2018 at https://doi. org/10.1016/j.ecolind.2017.09.005.
Nowell, L.H., Moran, P.W., Schmidt, T.S., Norman, J.E., Nakagaki, N., Shoda, M.E., Mahler, B.J., Van Metre, P.C., Stone, W.W., Sandstrom, M.W., and Hladik, M.L., 2018, Complex mixtures of dissolved pesticides show potential aquatic toxicity in a synoptic study of Midwestern U.S. streams: Science of the Total Environment, v. 613-614, p. 1469-1488, accessed February 2018 at http://dx.doi.org/10.1016/j.scitotenv.2017.06.156.

Rogers, H.A., Schmidt, T.S., Dabney, B.L., Hladik, M.L., Mahler, B.J., and Van Metre, P.C., 2016, Bifenthrin causes trophic and altered insect emergence in mesocosms: Implications for small streams: Environmental Science \& Technology, v. 50, no. 21, p. 11974-11983, accessed February 2018 at http:/ dx.doi.org/10.1021/acs.est.6b02761.

Shoda, M.E., Stone, W.W., and Nowell, L.H., 2016, Prediction of pesticide toxicity in Midwest streams: Journal of Environmental Quality, v. 45, p. 1856-1864, accessed February 2018 at http://dx.doi.org/10.2134/ jeq2015.12.0624

Van Metre, P.C., Alvarez, D.A., Mahler, B.J., Nowell, L.H., Sandstrom, M.W., and Moran, P.W., 2017, Complex mixtures of pesticides in Midwest U.S. streams indicated by POCIS time-integrating samplers: Environmental Pollution, v. 220, part A, p. 431-440, accessed February 2018 at http://dx.doi. org/10.1016/j.envpol.2016.09.085.

Van Metre, P.C., Frey, J.W., Musgrove, M., Nakagaki, N., Qi, S.L., Mahler, B.J., Wieczorek, M.E., and Button, D.T., 2016, High nitrate concentrations in some Midwest United States streams in 2013 after the 2012 drought: Journal of Environmental Quality, v. 45, no. 5, p. 1696-1704, accessed February 2018 at http://dx.doi.org/10.2134/jeq2015.12.0591.

Waite, I.R., and Van Metre, P.C., 2017, Multistressor predictive models of invertebrate condition in the Corn Belt, USA: Freshwater Science, v. 36, no. 4, p. 901-914, accessed February 2018 at https://doi.org/10.1086/694894.

\section{By Peter C. Van Metre, Barbara J. Mahler, Daren Carlisle, and James Coles}

Photographs by Peter Van Metre, USGS, unless otherwise noted. Cover photograph of boy holding fish courtesy of Michael Peirce, Creative Commons attribution 2.0 